\title{
SISTEM INFORMASI RENTAL KAMERA BERBASIS WEBSITE (STUDI KASUS : IFRAME RENTAL)
}

\author{
${ }^{1}$ Rizqi Sukma Kharisma, ${ }^{2}$ Bintang Yoga Pamungkas \\ ${ }^{1}$ Informatika, Ilmu Komputer, Universitas Amikom Yogyakarta, \\ ${ }^{2}$ Sistem Informasi, Ilmu Komputer, Universitas Amikom Yogyakarta, \\ Jalan Ringroad Utara, Condongcatur, Depok, Sleman, Yogyakarta Indonesia 55283 \\ Email:sukma@amikom.ac.id, bintang.9266@students.amikom.ac.id
}

(Diterima: 18 Februari 2020,direvisi: 21 April 2020, disetujui: 5 Mei 2020)

\begin{abstract}
Camera rental information system is a system used to enter camera borrowing transaction data into the database, so there are no errors when inputting, and making reports so that the results are under the expected data. Based on observations and interviews with the owners and employees of IFrame rental, information is obtained that the system in the IFrame rental transaction history is still manual. Therefore, the system that will be created by researchers is a web-based information system for recording the history of loan transactions. In addition to the process of input and output data, this information system also stores customer data. With this information system, it is expected to reduce the risk of losing old data that you want to use again. By implementing this information system to record rental history in IFrame, which is expected to reduce errors that might occur. This information system is also expected to accelerate the process of input and output which can ultimately help the admin and operator.
\end{abstract}

Keywords: Information System, Rental, Camera, Iframe, Bootstrap, Codeigniter, PHP.

\begin{abstract}
ABSTRAK
Sistem informasi rental kamera adalah sistem yang digunakan untuk memasukkan data transaksi peminjaman kamera ke dalam basis data, sehingga tidak ada kesalahan ketika dalam menginput, dan pembuatan laporan sehingga hasilnya sesuai dengan data yang diharapkan. Berdasarkan pengamatan dan wawancara dengan bagian pemilik dan karyawan penyewaan IFrame, diperoleh informasi bahwa sistem dalam riwayat transaksi sewa IFrame masih manual. Oleh karena itu, sistem yang akan dibuat oleh peneliti adalah sistem informasi berbasis web untuk mencatat riwayat transaksi pinjaman. Selain proses input dan output data, sistem informasi ini juga menyimpan data pelanggan. Dengan sistem informasi ini, diharapkan dapat mengurangi risiko kehilangan data lama yang ingin digunakan kembali. Dengan menerapkan sistem informasi ini untuk mencatat riwayat sewa di IFrame, yang diharapkan dapat mengurangi kesalahan yang mungkin terjadi. Sistem informasi ini juga diharapkan dapat mempercepat proses input dan output yang pada akhirnya dapat membantu admin dan operator.
\end{abstract}

Kata kunci: Sistem Informasi, Sewa, Kamera, Iframe, Bootstrap, Codeigniter, PHP.

\section{PENDAHULUAN}

Iframe Rental merupakan penyedia jasa penyewaan kamera beserta aksesorisnya yang berdiri sejak tahun 2012 dan berkantor pusat di jalan Yudistira, Nglempong Lor, RT.7/RW.22, Randuguang, Sariharjo, Kec. Ngaglik, Kabupaten Sleman, Daerah Istimewa Yogyakarta 55581. Jumlah pelanggan di Iframe Rental terus bertambah, sehingga data - data kamera maupun histori penyewaan kamera harus dicatat dalam suatu buku agar tersimpan dengan baik dan dapat dilihat kembali oleh pegawai ketika dibutuhkan.

Seluruh kegiatan pencatatan histori penyewaan kamera pada Iframe Rental masih dilakukan secara manual dengan menuliskannya pada buku besar sebagai pengingat data penyewaan terhadap kamera. Selain itu pencarian data histori penyewaan kamera juga dilakuan secara manual, pegawai harus mencari data kamera yang sudah dicatat di dalam buku besar ketika dibutuhkan. Pemilik Iframe Rental ingin meningkatkan pelayanan dengan menggunakan suatu sistem yang telah terkomputerisasi 
dan dapat pula melakukan proses pengolahan data secara valid. Pada sistem yang berjalan saat ini sering terjadi masalah seperti pada saat melakukan pencarian data sangat sulit dilakukan dan rawan terjadi kesalahan karena data yang sangat banyak. Selain itu, dengan pencatatan manual, resiko kehilangan data juga sering terjadi, seperti terselip maupun adanya kecelakaan di kantor. Pemilik Iframe ingin meminimalisir hal - hal tersebut akan tetapi karena sumber daya manusia yang terbatas, keinginan tersebut belum dapat diwujudkan.

Melihat permasalahan yang terjadi, penulis akan melakukan penelitian dan merancang sebuah sistem informasi penyewaan kamera yang ditujukan untuk Iframe Rental, yang diharapkan dapat membantu pegawai rental dalam mengakses dan mengolah setiap data - data yang berkaitan dengan histori penyewaan kamera, dan juga dapat mengetahui stok kamera dan aksesoris yang tersedia secara real-time tanpa mencari pada buku besar terlebih dahulu. Berdasarkan penjelasan diatas, penulis mengambil judul "Perancangan Sistem Informasi Rental Kamera Berbasis Website Menggunakan Framework Bootstrap dan CodeIgniter (Studi Kasus : Iframe Rental)

\section{TINJAUAN PUSTAKA}

Aplikasi Penyewaan Perlengkapan Studio Foto (Kamera dan Aksesoris) Berbasis Web di Cinema Kreatif Desain Pekanbaru membahas tentang meningkatkan kualitas penyewaan kamera dan perlengkapan studio foto dengan suatu sistem informasi yang diharapkan akan lebih efektif dan efisien. Metode yang digunakan untuk mengumpulkan data pada penelitian ini menggunakan metode observasi, wawancara, dan studi pustaka. Selain itu model yang digunakan dalam melakukan perancangan sistem adalah model pengembangan air terjun (waterfall). Hasil penelitian ini adalah sebuah sistem informasi untuk membantu karyawan dalam pengolahan data penyewaan kamera dan perlengkapan studio. [1]

Pengembangan Sistem Rental Kamera Online membahas tentang pembuatan sistem rental kamera terintegrasi yang diharapkan memudahkan penyewa dalam mencari kamera sesuai dengan kebutuhan. Dalam melakukan perancangan sistem ini, penulis menggunakan metode Unified Modeling Language (UML). Pada penelitian ini dihasilkan sebuah sistem informasi yang membantu menghubungkan antara penyewa dan pemilik persewaan sehingga dapat saling bertukar informasi kamera. [2]

Bangun Sistem Informasi Penyewaan Kendaraan (Sewadisini.com) Berbasis Website membahas tentang pembuatan sistem informasi yang dapat membantu penyedia jasa penyewaan dalam memasarkan kendaraannya dan membantu calon penyewa dalam mencari serta memesan kendaraan secara online. Dalam penelitian ini penulis menggunakan metode pengembangan air terjun (waterfall) dan pada pengujiannya menggunakan metode blackbox testing. Dalam implementasinya, Putu menggunakan framework bootstrap dan codeigniter. Hasil penelitian ini adalah sebuah sistem informasi penyewaan kendaraan berbasis website. [3]

Sistem Informasi Pemeliharaan Tempat Ibadah dalam Efektifitas Penyaluran Dana Sumbangan membahas tentang mempermudah pengelola dalam melaporkan kekurangan fasilitas atau kebutuhan pemeliharaan dalam sebuah tempat ibadah. Metode dalam melakukan perancangan sistem ini adalah dengan metode Unified Modeling Language (UML). Dalam implementasinya, Rengga menggunakan framework Yii yang menggunakan pola desain model-view-controller (MVC). Hasil penelitian ini adalah sebuah sistem informasi untuk untuk meningkatkan efektifitas penyaluran sumbangan guna pemeliharaan tempat ibadah. [4]

The Implementation of QR-Code Technology on Bulak Fish Center Information System membahas tentang penerapan teknologi QR-Code untuk mengakses sistem informasi pusat ikan Bulak Surabaya dalam menambahkan produk yang dihasilkan oleh penjual. Metode pengumpulan data yang digunakan menggunakan metode observasi dan wawancara. Hasil penelitian ini adalah sebuah sistem yang membantu penjual dalam melakukan pengelolaan produknya dengan adanya fitur QR-Code. [5]

Digitalization On Students Scoring System of SMPN 18 Bekasi membahas efektifitas pengelolaan dan penyampaian informasi penilaian sekolah. Dalam melakukan perancangan sistem ini penulis menggunakan dengan metode Unified Modeling Language (UML). Dari penelitian ini dihasilkan sebuah sistem informasi yang dinamakan SIADHEL yang artinya sistem informasi akademik delapan belas yang betujuan agar siswa/orangtua siswa dapat menerima informasi penilaian sekolah secara tepat, cepat dan akurat. [6] 
Perancangan Sistem Informasi Rental Mobil Berbasis Web pada PT. APM Rent Car membahas tentang optimalisasi promosi dan memudahkan calon pelanggan dalam melakukan rental mobil. Dalam melakukan perancangan sistem ini penulis menggunakan dengan metode Unified Modeling Language (UML). Hasil dari penelitian ini adalah sebuah sistem informasi yang dapat melakukan pengelolaan data rental dan pembuatan laporan. [7]

Sistem Informasi Penyewaan Rental Mobil Berbasis Web pada CV Adelia Transport membahas tentang memudahkan pelanggan dalam melakukan rental dan membantu penyebaran informasi. Metode pengembangan yang digunakan dalam penelitian ini adalah metode air terjun (waterfall). Hasil dari penelitian ini adalah sebuah sistem yang memudahkan pengguna melakukan rental dengan mudah. [8]

Aplikasi Penyewaan Mobil Berbasis Website (Studi Kasus pada Rental Mobil Lotus Purworejo) membahas tentang memudahkan penyedia melakukan pengelolaan data rental mobil. Metode pengembangan software yang digunakan adalah RAD (Rapid Application Development). Hasil penelitian ini adalah sebuah sistem yang dapat digunakan untuk memantau keterseduaan mobil untuk di-rental. [9]

Rancang Bangun Sistem Informasi Geografis Lokasi Debitur Berbasis Web membahas tentang memudahkan karyawan dealer dalam mencari lokasi debitur yang berpindah-pindah tempat tinggal. Metode pengembangan yang digunakan dalam penelitian ini adalah metode air terjun (waterfall). Hasil penelitian ini adalah sebuah sistem yang dapat digunakan untuk mendeteksi lokasi debitur yang melakukan pembayaran tidak tepat waktu dan bahkan tidak melunasi tagihan. [10]

Sistem Informasi Kepegawaian Berbasis Website Pada PT Sumatera Panca Rajo Palembang membahas tentang optimalsasi pengelolaan data karna terdapat resiko kehilangan dan kerusakan pada sistem sebelumnya. Penulis melakukan perancangan sistem ini dengan metode Unified Modeling Language (UML). Hasil dari penelitian ini adalah sebuah sistem informasi yang dapat melakukan pengelolaan kehadiran, data-data pegawai, mutasi, pemberhentian pegawai, dan perekrutan pegawai, serta dapat melakukan penilaian terhadap kinerja pegawainya. [11]

Development of Smart Nursing Homes Using Systems Engineering Methodologies in Industry 4.0 membahas tentang meningkatkan pelayanan dengan mengembangan sistem pintar pada panti jompo berbasis hostspot. Metode pengembangan software yang digunakan adalah V-Model. Hasil dari penelitian ini adalah rancangan sistem dan persyaratan perangkat keras untuk dapat mengimplementasikan sistem sehingga dapat memudahkan penghuni dalam melakukan sebuah aktifitas. [12]

Pembuatan Sistem Informasi Rental Mobil dengan Menggunakan Java dan Mysql membahas tentang optimalisasi pengelolaan data transaksi peminjaman mobil. Metode pengembangan yang digunakan penulis dalam penelitian ini adalah metode air terjun (waterfall). Hasil dari penelitian ini adalah sebuah sistem informasi yang dapat memudahkan pengguna dalam melakukan pengelolaan transaksi sehingga menjadi lebih cepat dan akurat. [13]

Dari penelitian-penelitian di atas terdapat perbedaan dengan penelitian yang dilakukan oleh penulis. Penulis membuat sistem informasi yang rental kamera pada Iframe Rental berbasis website. Dalam penelitian yang penulis menitik beratkan kepada manajemen penyewaan kamera dan menampilkan produk-produk pada website Iframe Rental. Produk yang ditampilkan juga menunjukkan ketersediaan barang, sehingga pelanggan dapat mengetahui ketersediaan produk yang akan disewa melalui website Iframe Rental. Penulis menggunakan peneliti menggunakan metode SDLC (System Development Life Cycle) dalam pengembangan sistem dan UML dalam perancangan sistemnya.

\section{METODE PENELITIAN}

Dalam penelitian ini metode pengumpulan data yang digunakan adalah metode observasi dan metode wawancara. Sejak berdiri, Iframe rental melayani lebih dari 12.000 transaksi baik dengan kustomer baru maupun transaksi dengan kustomer yang pernah melakukan transaksi di Iframe rental. Untuk mendapatkan data dari pemilik Iframe Rental peneliti menggunakan metode wawancara di mana dilakukan diskusi dan tanya jawab. D12ari sinilah peneliti mendapatkan data yang sesuai dengan permasalahan. 
Dalam penelitian ini metode perancangan yang dilakukan peneliti adalah dengan menggunakan UML (Unified Modeling Language). Dalam pengembangan sistem, peneliti menggunakan metode SDLC (System Development Life Cycle). Berikut merupakan tahapan dari SDLC. [14][15]

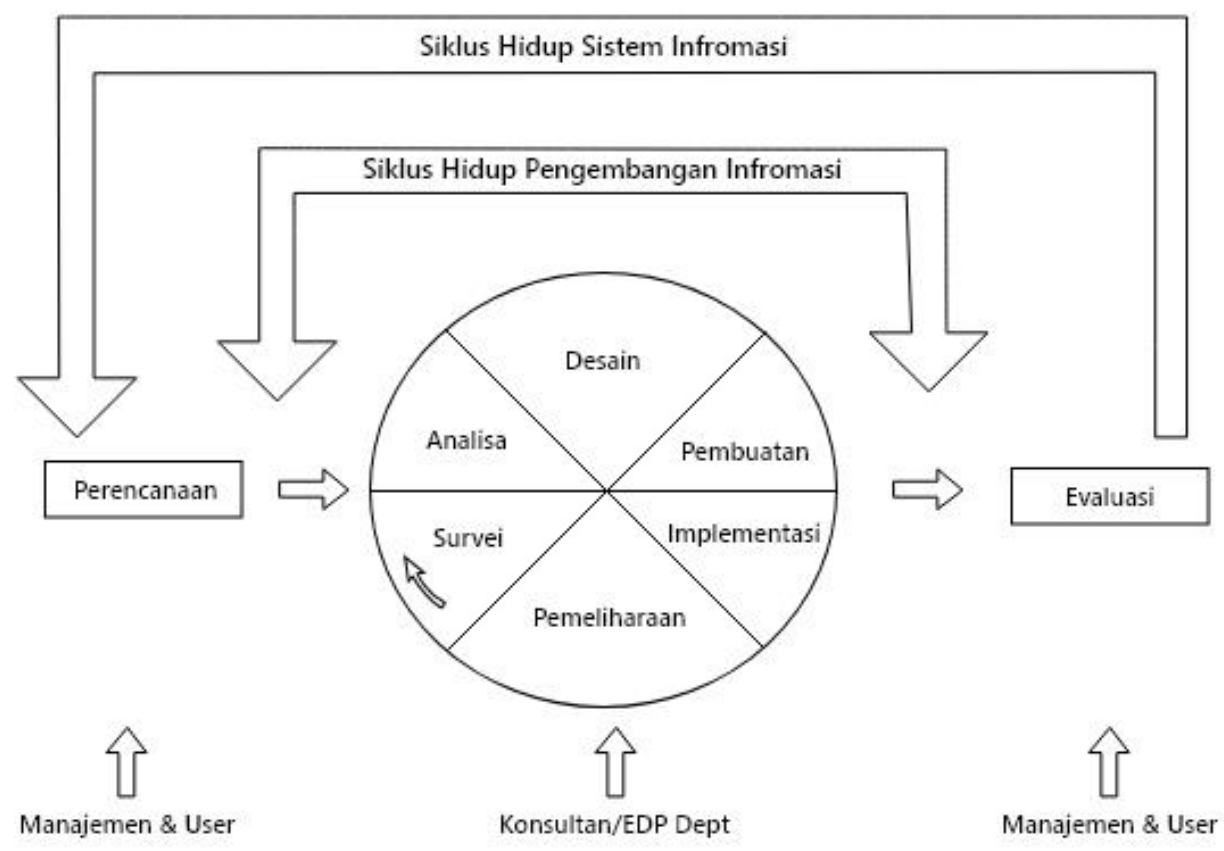

\section{Gambar 1 Siklus hidup pengembangan sistem informasi}

Dalam gambar 1 di atas terdapat dua fase dalam siklus hidup pengembangan sistem, yang pertama adalah perencanaan, yaitu identifikasi sasaran yang ingin dicapai dan yang kedua adalah fase pengembangan, yaitu mengyelidiki sistem lama untuk dijadikan landasan dari sistem baru. [14]

Dalam penelitian ini metode pengujian sistem menggunakan blackbox testing. Pengujian ini difokuskan pada pemenuhan kebutuhan yang disebutkan dalam spesifikasi, dengan cara menjalankan fitur yang ada sesuai modul, kemudian dilihat apakah hasilnya sudah sesuai dengan yang diinginkan.

\section{HASIL DAN PEMBAHASAN}

Hasil dari penelitian ini berupa aplikasi sistem informasi rental kamera berbasis website yang belum dapat diakses secara online, dan akan diupload apabila akan digunakan oleh Iframe Rental. Untuk dapat mengakses fitur yang ada, pengguna harus melakukan proses login terlebih dahulu sesuai dengan hak aksesnya.

\subsection{Perencanaan}

Pada tahapan ini peneliti melakukan perencanaan dan penyusunan aplikasi yang akan dibuat, tahap tersebut meliputi perangkat lunak untuk membangun aplikasi dan arsitektur aplikasi berupa pemodelan sistem dalam bentuk use case, class diagram dan activity diagram. Perangkat lunak yang digunakan untuk membangun sistem yaitu Visual Studio Code untuk membuat baris kode dan XAMPP sebagai webserver lokal untuk mengelola database sistem.

Rancangan use case diagram sistem seperti pada Gambar 2 dapat dilihat bahwa, aktor/user dalam sistem ini terdiri dari administrator, operator, dan pengunjung. Untuk dapat mengakses sistem administrator dan operator rental harus melakukan login agar dapat mengakses menu atau fungsi yang tersedia pada sistem. Menu yang dapat diakses oleh administrator antara lain

Menu data role, menu data menu, menu data submenu, menu data provinsi, menu data kabupaten, menu data kecamatan, menu data kelurahan, menu data user, menu data setting. Sedangkan menu yang dapat diakses oleh operator rental antara lain menu data customer, menu data 
peminjaman, menu data pengembalian, menu data riwayat denda, menu data produk, menu data kategori produk, menu data transaksi harian, meu data transaksi selesai.

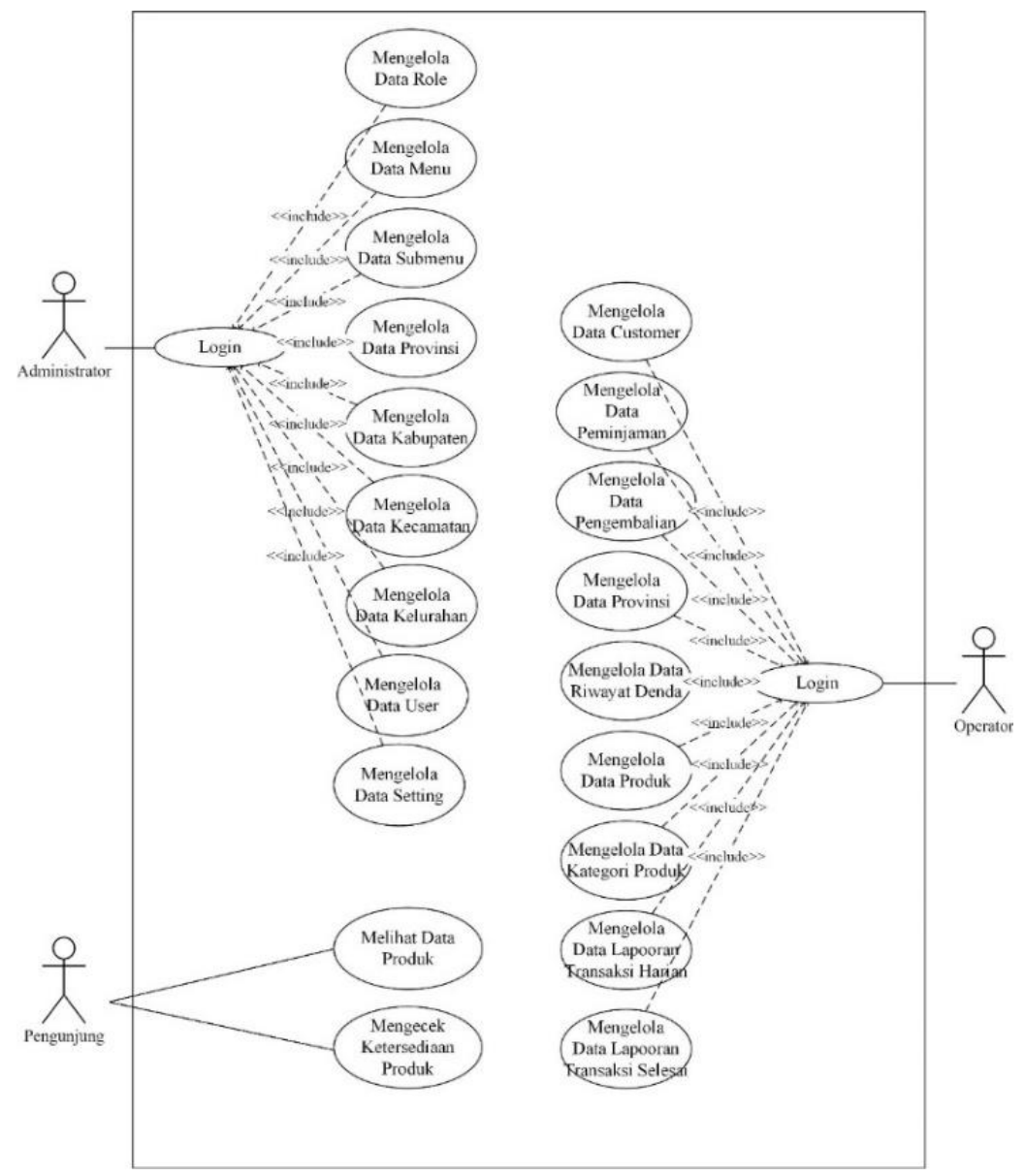

Gambar 2 Use Case Diagram

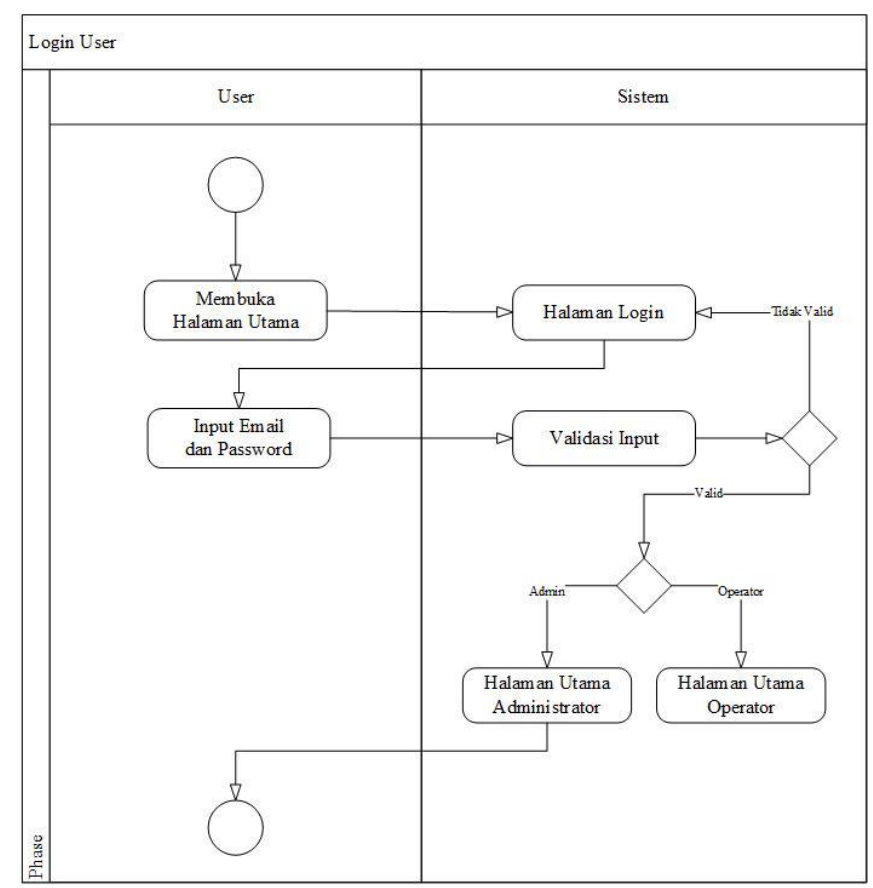

Gambar 3 Activity diagram login user

Kharisma, Perancangan Sistem Informasi Rental Kamera Berbasis Website (Studi Kasus : Iframe Rental) 
Activity diagram menunjukkan interaksi yang dilakukan oleh aktor terhadap sistem. Activity diagram sistem ini terdiri dari activity digram untuk administrator, activity digram untuk operator, dan activity diagram untuk pengunjung. Activity diagram user pada saat login dapat dilihat pada Gambar 3.

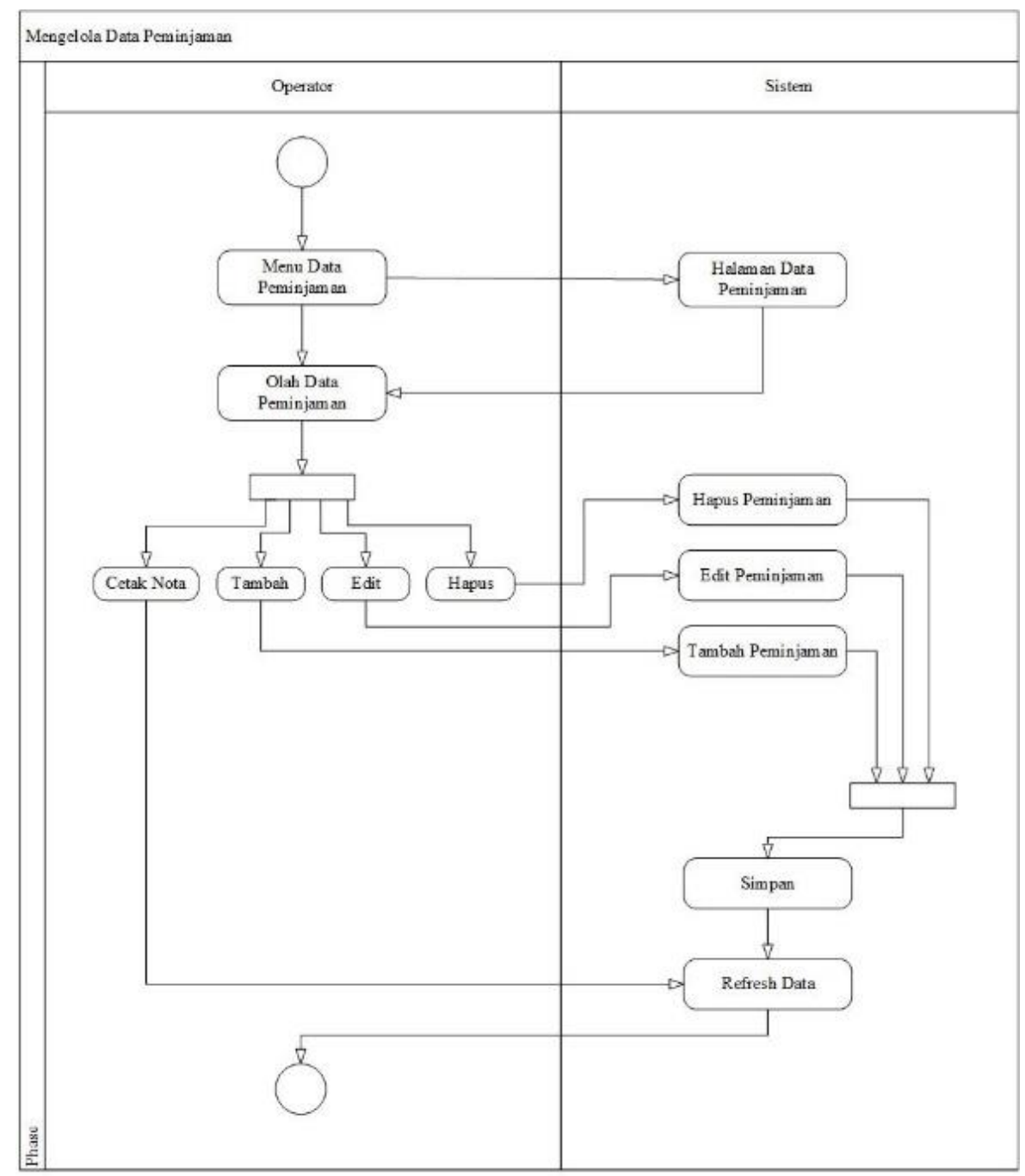

Gambar 4 Activity diagram data peminjaman

Dari gambar 4 dapat dilihat bahwa aktor pengguna untuk dapat masuk kedalam sistem harus membuka halaman login terlebih dahulu, kemudian menginputkan email dan password. Sistem akan melakukan validasi, apabila tidak valid maka kembali pada halaman login, namun apabila valid maka akan berlanjut ke pengecekan role. Apabila role yang tervalidasi adalah admin, maka halaman akan dialihkan ke halaman utama administrator, namun apabila role yang tervalidasi adalah operator, maka halaman akan dialihkan ke halaman utama operator.

Dari gambar 4 dapat dilihat bahwa aktor operator apabila melakukan proses peminjaman maka harus membuka halaman data peminjaman, lalu operator memilih opsi olah data, diantaranya adalah cetak nota, tambah, edit, dan hapus. Apabila memilih cetak nota, maka halaman akan langsung dimuat untuk mencetak nota sesuai dengan nota transaksi yang dipilih, namun apabila operator memilih opsi tambah, edit, atau hapus, maka halaman akan dialihkan ke masing-masing opsi untuk olah data dan terdapat proses penyimpanan, kemudian halaman akan dimuat kembali. 
Dari gambar 5 dapat dilihat bahwa aktor administrator apabila melakukan proses olah data role maka harus membuka halaman role, lalu administrator memilih opsi olah data, diantaranya adalah akses, tambah, edit, dan hapus. Apabila memilih akses, maka halaman akan langsung dimuat untuk olah akses sesuai dengan user yang dipilih, namun apabila administrator memilih opsi tambah, edit, atau hapus, maka halaman akan dialihkan ke masing-masing opsi untuk olah data dan terdapat proses penyimpanan, kemudian halaman akan dimuat kembali.

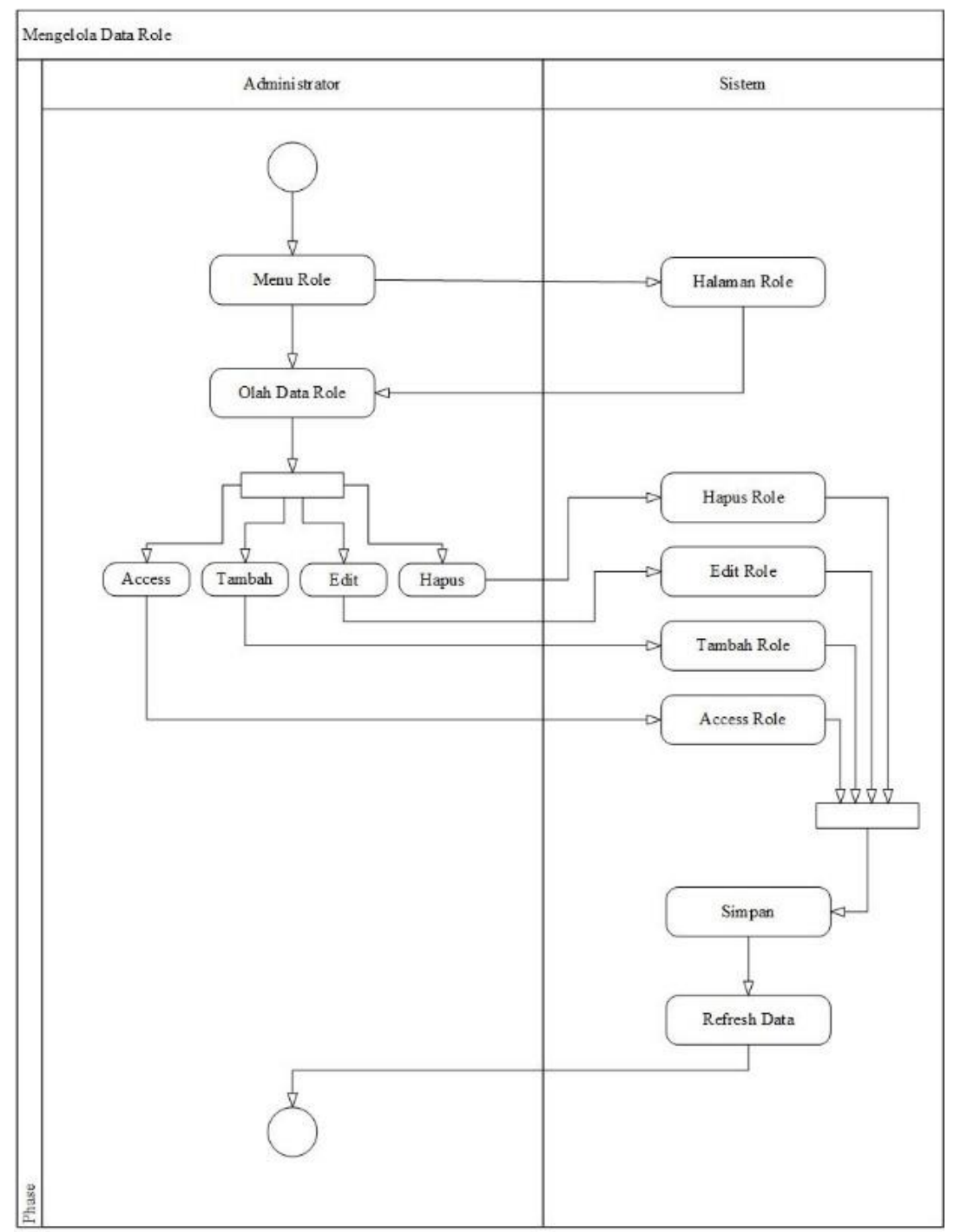

Gambar 5 Activity diagram data role

Class diagram adalah diagram statis. Ini mewakili pandangan statis dari suatu aplikasi. Class diagram tidak hanya digunakan untuk menggambarkan, memvisualisasikan, dan mendokumentasikan berbagai aspek sistem tetapi juga untuk membangun kode eksekusi (execurable code) dari aplikasi perangkat lunak. [15] Class diagram controller dapat dilihat pada gambar 6. 


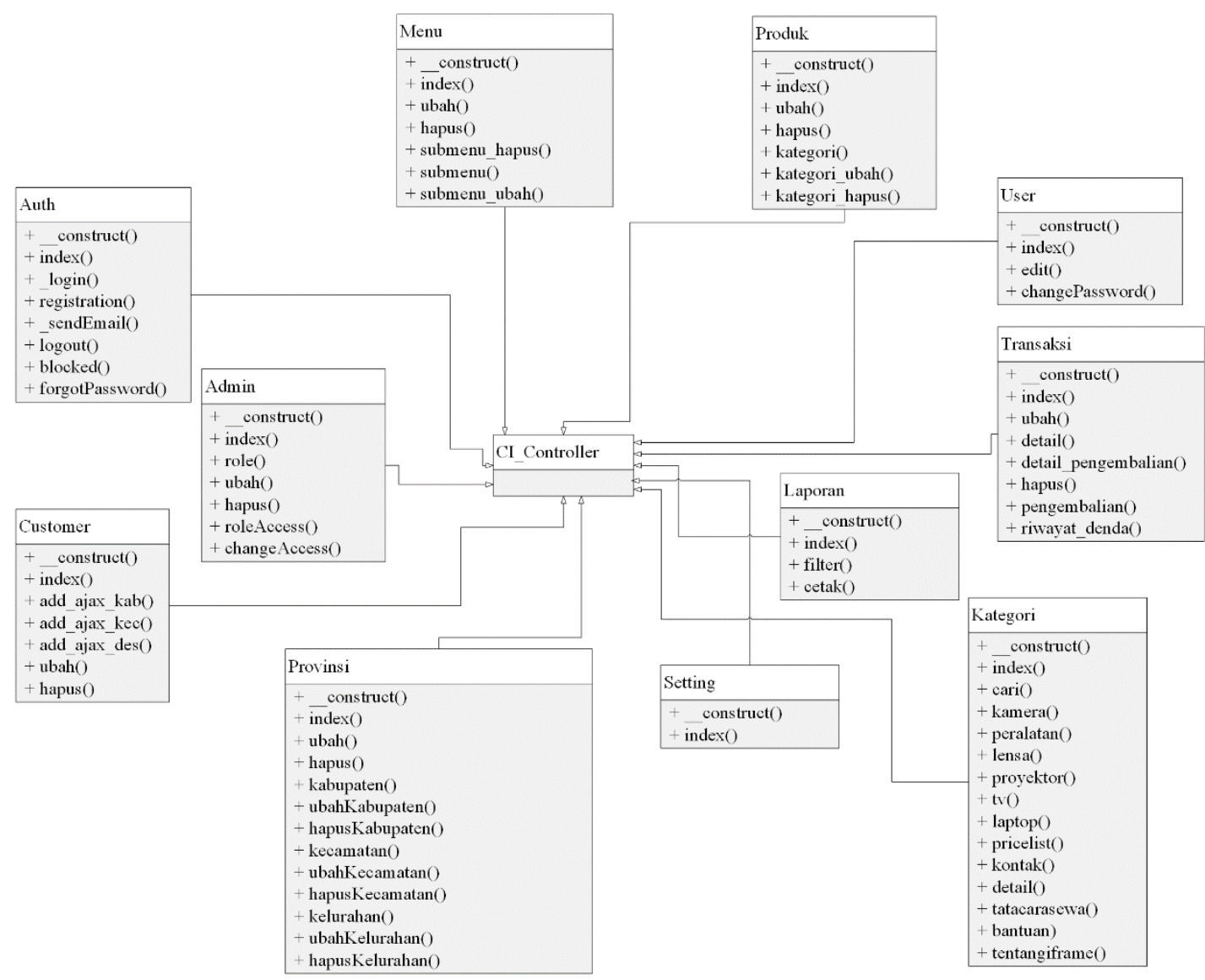

\section{Gambar 6 Class diagram controller}

Pada gambar 7 merupakan rancangan dashboard yang dapat diakses oleh administrator untuk memantau perkembangan transaksi. Administrator hanya perlu membuka halaman ini untuk melihat ringkasan jumlah pelanggan baru, total pelanggan, total transaksi aktif, total transaksi bulan ini, dan total pemasukan.

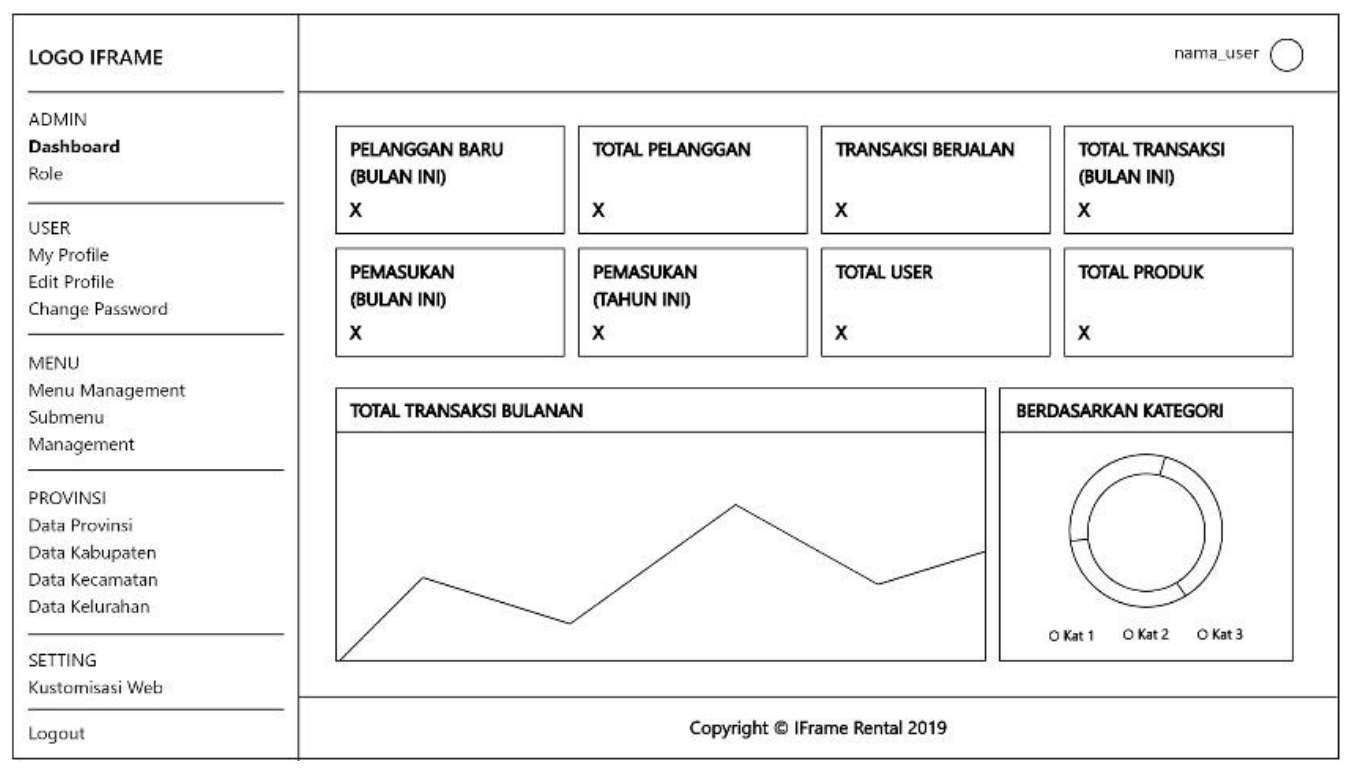

Gambar 7 Rancangan dashboard administrator

Kharisma, Perancangan Sistem Informasi Rental Kamera Berbasis Website (Studi Kasus : Iframe Rental) 
Antar muka pengguna merupakan interaksi antara pengguna dengan komputer. Perancangan antar muka penting untuk membuat tampilan yang memberikan kemudahan pengguna dalam menggunakan aplikasi. Perancangan antar muka dari sistem rental ini dibuat dengan tampilan yang sederhana sehingga membantu penggunanya. Gambar 8 merupakan rancangan tampilan homepage atau halaman depan yang dapat digunkan pengunjung untuk mengecek ketersediaan alat. Pada hero section terdapat searchbox yang besar untuk menginputkan nama alat yang ingin dicari. Selanjutnya pada section berikutnya adalah daftar alat yang popular dan sering di pinjam. Dashboard administrator menampung data ringkasan transaksi sehingga ketika administrator melihat halaman dashboard dapat langsung membuat kesimpulan berdasarkan data.

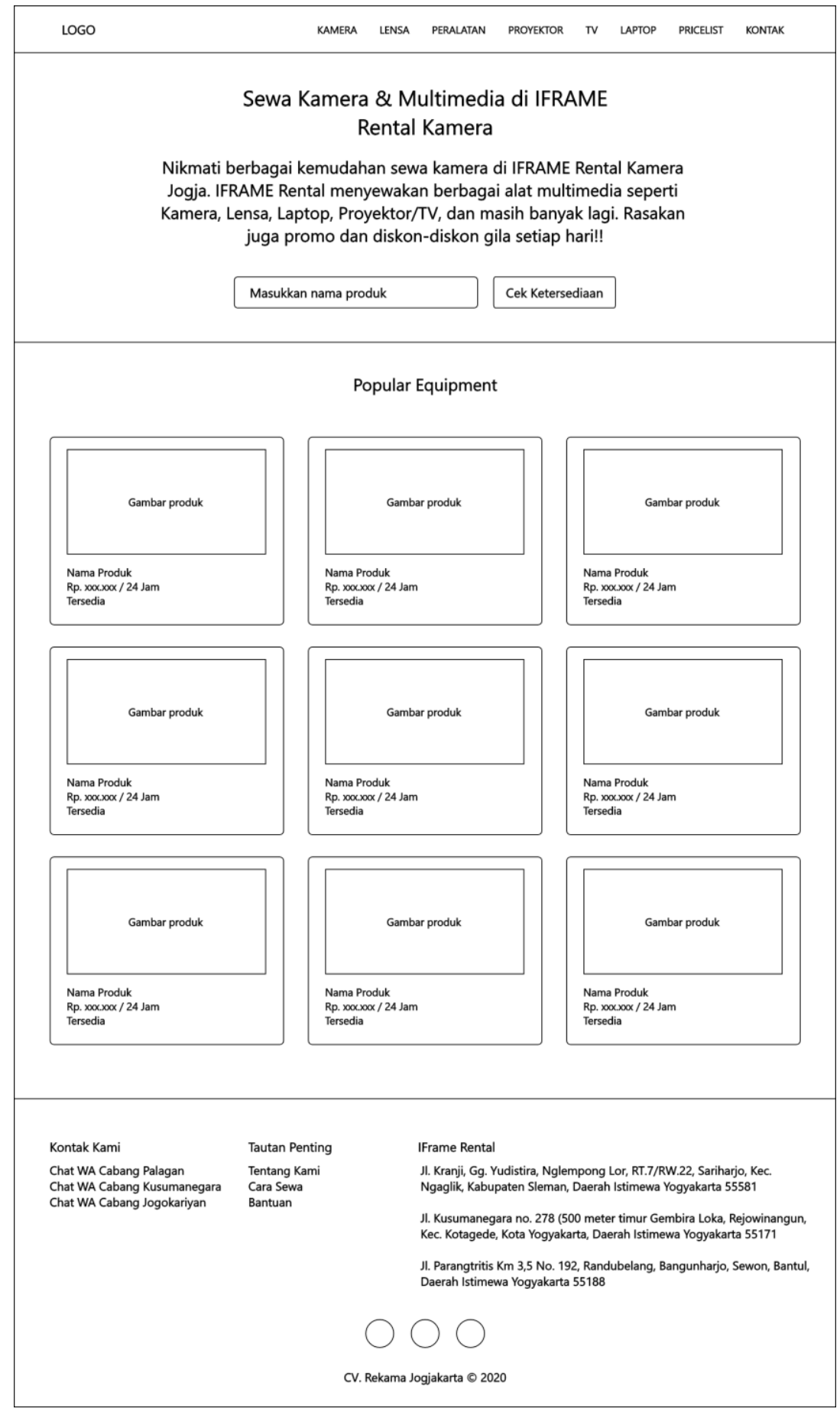

Gambar 8 Rancangan halaman depan 


\subsection{Pengembangan}

Pada tahap pengembangan, rancangan aplikasi sistem diterjemahkan ke dalam bentuk aplikasi yang sebenarnya dan siap diuji coba. Pada gambar 9 merupakan tampilan halaman depan yang akan digunakan pengunjung untuk mencari dan mengecek apakah alat tersedia untuk disewa.

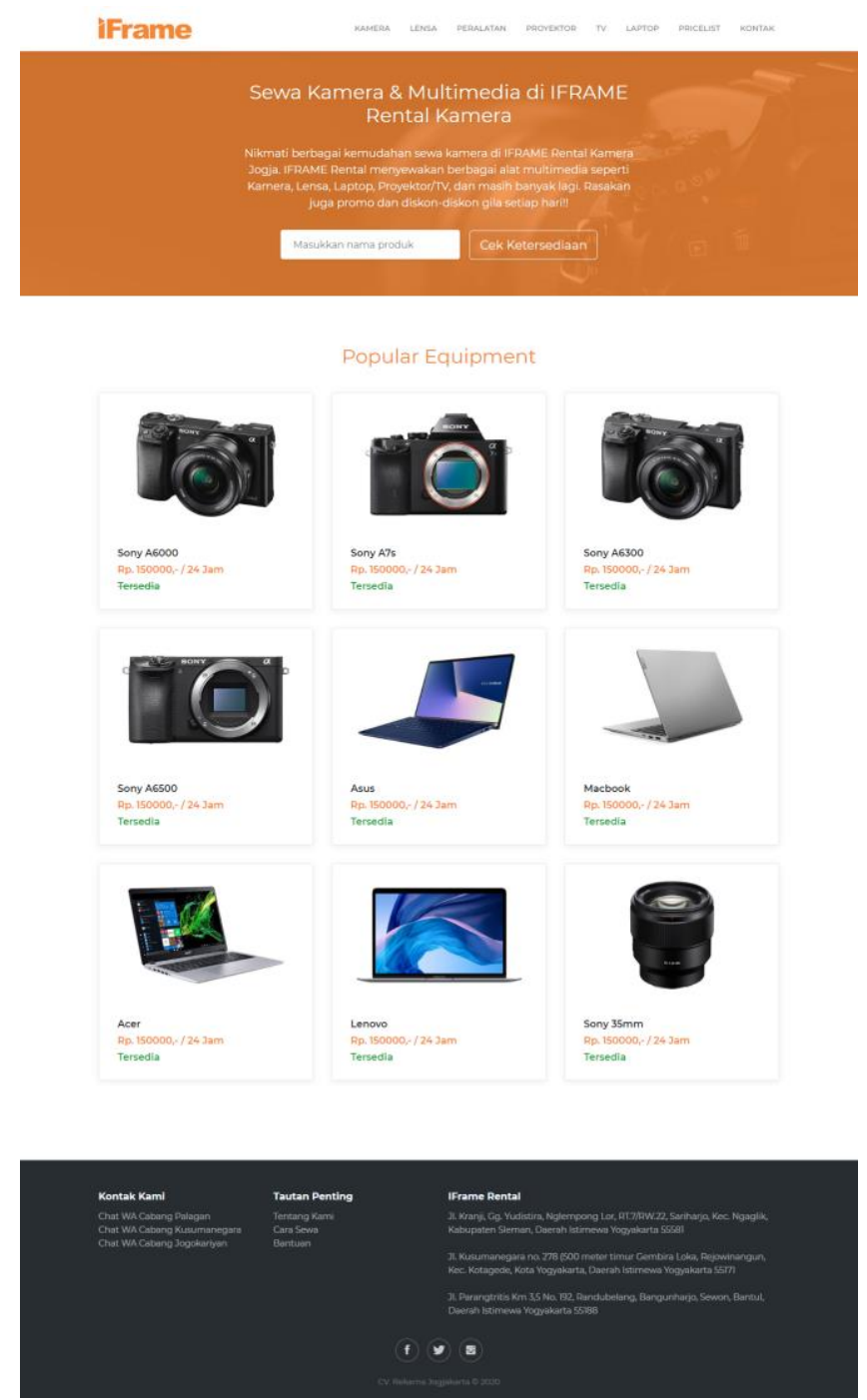

Gambar 9 Halaman depan

Pada gambar 10 merupakan tampilan dashboard yang hanya dapat diakses oleh administrator. Halaman ini berisi ringkasan dari transaksi yang dilakukan dalam sistem ini, mulai dari data pemasukan, total customer \& produk, grafik transaksi dan peminjaman. 


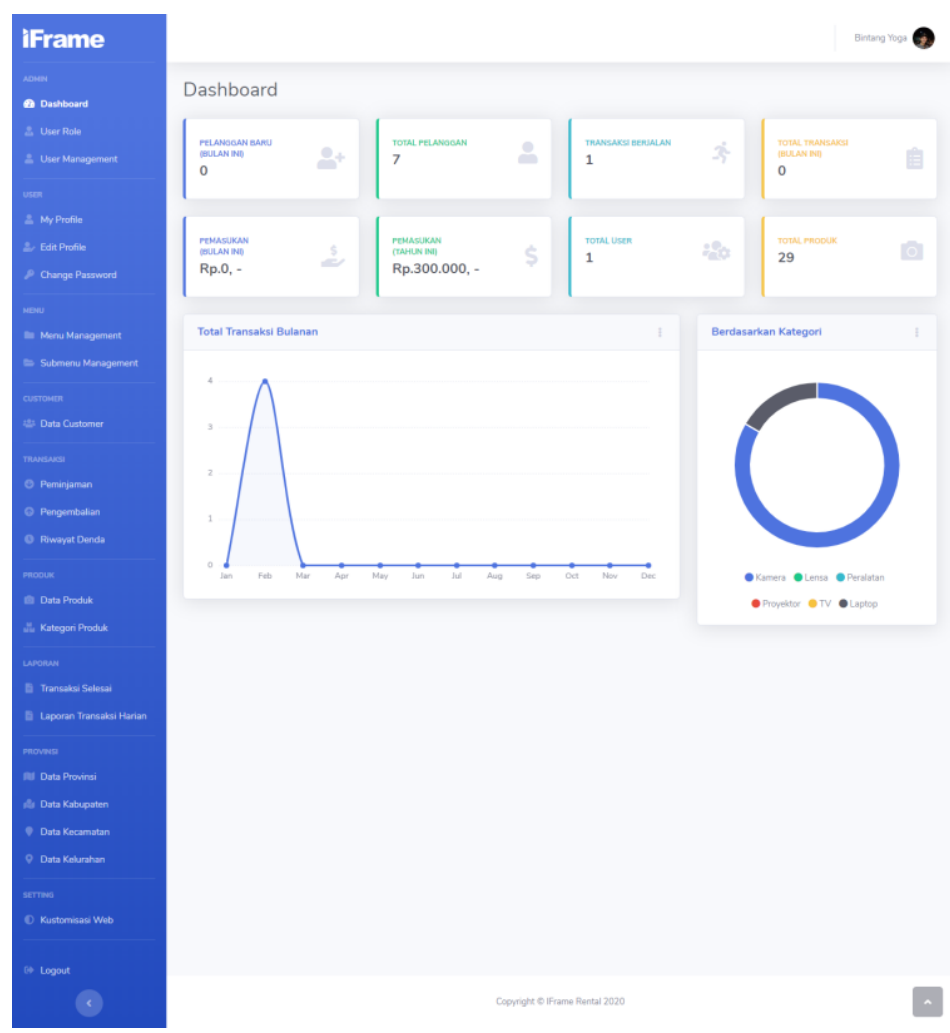

\section{Gambar 10 Halaman dashboard administrator}

\subsection{Pengujian}

Tahapan terakhir adalah tahapan pengujian sistem. Pada tahap ini dilakukan pengujian terhadap aplikasi sistem informasi yang sudah dibuat, serta melakukan perbaikan apabila terdapat kode program atau bagian dari perangkat lunak yang tidak berjalan sesuai tujuan. Pengujian dilakukan dengan metode blackbox testing, adapun hasil pengujian ditunjukkan pada tabel berikut :

Tabel 1 berikut menunjukkan hasil pengujian fitur login

Tabel 1 Pengujian Halaman Login

\begin{tabular}{cccc}
\hline Fitur / Menu & Bagian yang Diuji & Status & Penguji \\
\hline Login & $\begin{array}{c}\text { Tampilan } \\
\text { Proses }\end{array}$ & Sukses & Admin \\
\hline
\end{tabular}

Tabel 2 menunjukkan pengujian menu peminjaman beserta aksi didalamnya

Tabel 2 Pengujian Menu Peminjaman

\begin{tabular}{ccll}
\hline Fitur / Menu & Bagian yang Diuji & Status & Penguji \\
\hline Add New Peminjaman & $\begin{array}{c}\text { Tampilan } \\
\text { Proses }\end{array}$ & Sukses & Admin \\
\hline Selesai & $\begin{array}{c}\text { Tampilan } \\
\text { Proses }\end{array}$ & Sukses & Admin \\
\hline Edit & $\begin{array}{c}\text { Tampilan } \\
\text { Proses }\end{array}$ & Sukses & Admin \\
\hline Delete & $\begin{array}{c}\text { Tampilan } \\
\text { Proses }\end{array}$ & Sukses & Admin \\
\hline
\end{tabular}

Tabel 3 menunjukkan pengujian menu laporan transaksi harian beserta aksi didalamnya 
Tabel 3 Pengujian Menu Laporan Transaksi Harian

\begin{tabular}{cccc}
\hline Fitur / Menu & Bagian yang Diuji & Status & Penguji \\
\hline Data Transaksi Harian & $\begin{array}{c}\text { Tampilan } \\
\text { Proses }\end{array}$ & Sukses & Admin \\
\hline Cetak PDF & $\begin{array}{c}\text { Tampilan } \\
\text { Proses }\end{array}$ & Sukses & Admin \\
\hline
\end{tabular}

\section{KESIMPULAN}

Kesimpulan dari penelitian ini adalah telah dibuatnya sebuah aplikasi bernama "Sistem Informasi Rental Berbasis Website Menggunakan Framework Bootstrap dan CodeIgniter" yang memiliki fitur yaitu : Sistem ini dapat melakukan pencarian barang sesuai dengan kata kunci yang dimasukkan kustomer, sistem ini dapat menampilkan informasi status barang yang dapat dipinjam (tersedia) maupun barang yang tidak dapat dipinjam (tidak tersedia), sistem ini dapat melakukan pengelolaan stok barang, sistem ini menyimpan data kustomer sehingga ketika terjadi transaksi berulang dengan kustomer yang sama tidak perlu melakukan input data ulang, sistem ini dapat melakukan pengarsipan maupun pembuatan laporan, baik laporan harian maupun laporan bulanan dan sistem ini dapat melakukan perhitungan denda secara otomatis

\section{REFERENSI}

[1] Y. Yulisman, "Aplikasi Penyewaan Perlengkapan Studio Foto (Kamera dan Aksesoris) Berbasis Web di Cinema Kreatif Desain Pekanbaru," J. Teknol. Sist. Inf. dan Apl., vol. 2, no. 1, p. $15,2019$.

[2] R. Saputra, Widodo, A. B. Wahyu, and A. Hendra, "Pengembangan Sistem Rental Kamera Online," J. Pengemb. Teknol. Inf. dan Ilmu Komput., vol. 2, no. 6, pp. 2221-2226, 2018.

[3] P. Agus et al., "Penyewaan Kendaraan ( Sewadisini . Com )," J. Teknol. Inf. dan Komput., vol. 6, no. 1, pp. 66-77, 2020.

[4] R. Asmara, A. S. Ahsan, and M. O. Rachmawan, "Sistem Informasi Pemeliharaan Tempat Ibadah Dalam Efektifitas Penyaluran Dana Sumbangan,” Sistemasi, vol. 9, no. 1, p. 176, 2020.

[5] F. Liantoni, S. Rosetya, and W. M. Rahmawati, "The Implementation of QR-Code Technology on Bulak Fish Center Information System,” J. Online Inform., vol. 3, no. 2, p. 123, 2019.

[6] F. A. S. N. Haq and N. Nuryuliani, "Digitalization On Students Scoring System of SMPN 18 Bekasi," IJCCS (Indonesian J. Comput. Cybern. Syst., vol. 13, no. 3, p. 283, 2019.

[7] Y. Heriyanto, "Perancangan Sistem Informasi Rental Mobil Berbasis Web Pada PT.APM Rent Car," J. Intra-Tech, vol. 2, no. 2, pp. 64-77, 2018.

[8] R. Triwibowo, N. B. Ginting, and F. Fatimah, "Sistem Informasi Penyewaan Rental Mobil Berbasis Web Pada CV Adelia Transport," SINTAK2019, no. November, pp. 254-261, 2019.

[9] N. Hasan, "APLIKASI PENYEWAAN MOBIL BERBASIS WEBSITE ( Studi Kasus pada Rental Mobil Lotus Purworejo )," Bianglala Inform., vol. 7, no. 2, pp. 117-121, 2019.

[10] N. M. R. Mamulak, "Rancang Bangun Sistem Informasi Geografis Lokasi Debitur Berbasis Web," JATISI (Jurnal Tek. Inform. dan Sist. Informasi), vol. 5, no. 1, pp. 12-23, 2018.

[11] E. D. Nurmawan and M. Mulyati, "Sistem Informasi Kepegawaian Berbasis Website Pada PT Sumatera Panca Rajo Palembang," JATISI (Jurnal Tek. Inform. dan Sist. Informasi), vol. 5, no. 2, pp. 147-157, 2019.

[12] F. Cui, L. Ma, G. Hou, Z. Pang, Y. Hou, and L. Li, "Development of smart nursing homes using systems engineering methodologies in industry 4.0," Enterp. Inf. Syst., vol. 14, no. 4, pp. 463-479, 2020.

[13] A. Rahmawati, R. Kridalukmana, and I. P. Windasari, "Pembuatan Sistem Informasi Rental Mobil dengan Menggunakan Java dan Mysql," J. Teknol. dan Sist. Komput., vol. 3, no. 3, p. $335,2015$.

[14] T. Sutabri, Analisa Sistem Informasi. Yogyakarta: CV. Andi Offset, 2012.

[15] Munawar, Analisis Perancangan Sistem Berorientasi Objek dengan UML (Unified Modelling Language). Bandung: Informatika, 2018. 